may be considerable disturbance of function. All parts of the nerve can be recognized as contributors to the tumour process.

\section{Tumours of Bone}

There were six cases of enchondroma in the 300 . Jaffe and Lichtenstein (1943) describe this tumour as the solitary benign enchondroma of bone. They emphasize that it must be distinguished from the osteuchondroma (or solitary exostosis or ecchondrosis) and also from Ollier's disease, in which there are multiple lesions. It is the commonest bone tumour in the hand.

There were 10 cases of this tumour in all. Six were in males, and eight were in the left hand. All were in phalanges (one in T.P., five in M.P.. three in P.P., and one multiple). The average age of the patients was 33 , spread fairly evenly from 5 to 57 . Five males and one female attended with a pathological fracture after a minor injury. Three females and one male sought treatment because of a tender swelling. Eight of the 10 cases were treated by surgery with curettage, and most were packed with bone chips. though two were left unpacked following Mason's (1954) advice that the small ones heal quite adequately by ossification of the haematoma that develops in the cavity.

It is surprising how much of the rice-grain-like cartilaginous material can be curetted out of these tumours. It is advised that in order to prevent a recurrence none should be left, and some authors suggest that the cavity should be washed out with iodine or some other medicament for the same reason.

The $x$-ray appearance is of a translucent area in the shaft of the phalanx. It is usually lobulated, with some trabeculation, and occasionally there are areas of ossification within the tumour. Frequently a pathological fracture is present. There is wide acceptance of the theory that they are congenital in origin, arising from cell-rests.

The lesion always starts in the metaphysis, and does not spread to the epiphysis unless the patient is fully grown.

The cortex of the shaft is thinned and often expanded. The diagnosis from osteoclastoma would be difficult were not that tumour so very rare in the hand. When it does occur it is usually in the metacarpals.

The fragments examined microscopically usually show cartilage with mature-looking cells and much mucoid degeneration of the ground substance. The cells are regular and without conspicuous mitoses. Occasionally there are areas of ossification.

\section{Tumour-forming Entities}

Pyogenic Granuloma.-This interesting clinical entity is commoner than at one time thought. It occurs most often on the volar surface of the hand and fingers, where the skin is much thicker than elsewhere. It arises when infection follows an injury in which there is some loss of skin, or in which skin apposition is not obtained or is prevented by infection.

A granulation grows through the opening in the skin and spreads out like a mushroom above it. Epithelization cannot occur. Daily application of silver nitrate progressively reduces the size of the granulation and deals with the associated infection, and epithelization occurs across the wound when the granulations are reduced below skin level.

\section{Summary}

Few series of figures for the incidence of tumours of the hand have been published, and the proportiun of malignancies in some of them appeared to be unduly high.

300 consecutive swellings in the hand seen in a casualty and orthopaedic unit of a big general hospital are analysed here to give an estimate of the propuruons in which these tumours appear.

$61 \%$ were ganglia, $10 \%$ epidermoid cysts, and all the remainder -27 different diagnoses in all-made up $29 \%$.

There were 46 neoplasms, of which only two were malignant.

Salient clinical features and points of diagnosis of the various tumours are discussed and their relative frequency is indicated.

The treatment of most of these tumours is by excision, and the ideal condition for this is whth a tournıquet under general anaesthesia.

My thanks are due to Mr. J. G. Bonnin, who suggested this study, and to Mr. R. G. Pulvertaft for much helpful advice.

\section{REPERENCBS}

Carp, L., and Stout A. P (1928) Surg Gvnec, Obstet $47,460$. De Orsay, R. H., Mecray, P. M., and Ferguson, L. K. (i937). Amer. J. Surg., 36, 313

Gross, R. E. (1937). Surg. Gynec. Obstet. 65, 289.

Jatfe, H. L., and Lichtenstein, L. (1943). Arch. Surg. (Chicago), 46, 480 .

Jenkins, S. A. (1952). J. Bone Jt Surg,. 34B, 401.

Jones, H. Morus (1953). Brit. J. Surg., 41, 63

King, E. S. J. (1932). Aust. N.Z. J. Surg., 1, 367.

- (1933). Brit. J. Surg., 21, 29.

Ledderhose (1893). Dtsch. Z. Chir., 37, 102

Mason, M. I. (1954). Minn. Med., 37, 600.

Stewart, M. J. (1948). Ibid., 30B, 522

Willis, R. A. (1953). Pathology of Tumours, 2nd ed. Butterworth, London

Wright, C. J. E. (1951). Brit. J. Surg., 38, 257.

\section{PHYSICAL ACTIVITY OF PATIENTS AFTER THE ONSET OF ACUTE CARDIAC INFARCTION}

BY

KLAUS A. J. JÄRVINEN, M.D.

Lecturer in Internal Medicine, University of Helsinki ; Assistant Physician-in-Chief at the Medical Department, Maria Hospital, Helsinki, Finland

Complete physical rest is commonly held to be the guiding principle in the treatment of acute myocardial infarction (Miller, 1942 ; White, 1944 ; Scherf and Boyd, 1947 ; Friedberg, 1949 ; Blumgart, 1955 ; Levine. 1958). The slightest physical exertion in these cases is regarded as potentially lethal. But does the person with an acute myocardial infarct in fact do what be should ? It is often found that an attack is immediately followed by a state of marked restlessness in the patient, associated with severe pain. He cannot remain quiet in bed, but tends to move or even gets up and walks about the room in his agony (Warburg, 1943 ; McLeod, 1949).

The object of this paper is to present my observations on the activities, and especially the physical exertions, of patients with acute myocardial infarction from the onset of the attack to the time when medical aid was sought. 


\section{Material}

The series consisted of 102 men and 31 women, all from Helsinki, admitted to the emergency ward of the Maria Hospital in 1957. Their activities from the onset of the acute myocardial infarct to the time when they first received medical aid could be ascertained in full detail. The series included only clinically frank cases of acute myocardial infarction with typical signs of severe pain. Further criteria for inclusion in the series were distinct changes in the electrocardiogram, an elevated white blood count, and a definite rise in the glutamic serum transaminase (S.G.O.T.) value, in the erythrocyte sedimentation rate, and in the temperature. A few cases, however, were included though they did not fill all the abuve criteria. In these the presence of a massive acute myocardial infarct was ascertained by other means-for instance, by necropsy in fatal cases.

The average age of the 102 men in the present series was 51.4 years, the youngest being 36 and the oldest 81 . Ten of these died during the first week in hospital and eight during the subsequent five weeks (from the second to the sixth week in hospital). Necropsy was performed on 17.

The average age of the 31 women in the series was 62.0 years, the youngest being 35 and the oldest 88 . Seven of the women died during the first week in hospital and two during the subsequent five weeks. Necropsy was performed on eight.

\section{Activity After the Attack}

In studying the histories the first point established was the distance that the patient with an acute myocardial infarct walked before seeking medical aid. The group of patients who walked the shortest distance $(0-20 \mathrm{~m}$.) comprised also those in whom the infarct produced a state of restlessness that made them pace about the room, visit the lavatory, and so on. In many of these cases the total distance walked must have exceeded $20 \mathrm{~m}$., but an accurate assessment could not be reached. The results are given in Table $I$.

The time of stopping work was ascertained in all those cases in which the patient had an attack while at work. Of the 38 men who were at work, 21 stopped immediately at the onset of the attack. But in spite of the pain 17 continued working (either without a pause or after resting a moment) for at least one hour after the onset of the attack. Nine of them continued at work till the end of the day, and two even returned to work on the following day. Of the 17 men who continued working, five became so weak as to be unable to move and were therefore taken direct to the Maria Hospital, five went to the doctor or the hospital unaided, and seven went home first and later consulted a physician or visited the hospital.

TABLS I.-Distance Walked by Patients with Acute Myocardial Infarction Before Recourse to Medical Aid

\begin{tabular}{|c|c|c|c|c|c|c|c|}
\hline \multirow{2}{*}{\multicolumn{2}{|c|}{$\begin{array}{l}\text { Dhatance } \\
\text { in Motres }\end{array}$}} & \multicolumn{3}{|c|}{ Mon } & \multicolumn{3}{|c|}{ Women } \\
\hline & & $\begin{array}{l}\text { Under } \\
60\end{array}$ & $\underset{60}{\text { Over }}$ & Total & $\begin{array}{l}\text { Under } \\
\mathbf{6}\end{array}$ & Over & Total \\
\hline $\begin{array}{cc}0-20 & \cdots \\
20-50 & \cdots \\
50-100 & \cdots \\
100-500 & \cdots \\
500-1,000 \\
\text { Over } 1,000\end{array}$ & $\begin{array}{l}\because \\
\because \\
\ddot{0}\end{array}$ & $\begin{array}{r}15 \\
8 \\
10 \\
12 \\
11 \\
9\end{array}$ & $\begin{array}{r}14 \\
5 \\
3 \\
10 \\
3 \\
2\end{array}$ & $\begin{array}{l}29 \\
13 \\
13 \\
22 \\
14 \\
11\end{array}$ & $\begin{array}{l}5 \\
1 \\
1 \\
1 \\
=\end{array}$ & $\begin{array}{l}19 \\
\frac{3}{1} \\
\frac{1}{-}\end{array}$ & $\begin{array}{r}24 \\
1 \\
2 \\
=\end{array}$ \\
\hline No. of cases & .. & 65 & 37 & 102 & 8 & 23 & 31 \\
\hline
\end{tabular}

Of the women, seven were working away from home when the attack occurred. All of them stopped work at once.

Forty-seven of the men were at home at the onset of the attack, and in 24 cases a physician was called to the patient's home, while 23 patients went to consult a doctor or sought advice at the medical out-patient department of the Maria Hospital.

Eighteen of the women were at home when the attack occurred, and in 15 cases a physician was called to the patient's home, while three patients went to the hospital for aid.

Fifty-five men had an attack away from home, and in only three cases was a physician called to see the patient where the attack occurred. In eight cases the myocardial infarct was accompanied by severe shock, so that the patient was unable to stand up and was therefore taken to hospital. Nine men went at once to consult a doctor or to visit the out-patient department of the Maria Hospital. Another group of 18 men went home immediately after the onset of the attack, and in eight of these cases a physician was later called to the patient, whereas the remaining 10 left home again to consult a private practitioner or to go to hospital.

Thirteen woman had an attack away from home. In two cases a doctor was called to the patient. Five of the women were unable to move on account of shock, and were taken to hospital. The remaining six went to hospital unaided.

Table II shows how the patients made their way to the medical attendant. The time that elapsed from the onset of acute myocardial infarction to the first recourse to medical assistance is shown in Table III.

TABLB II.-Mode of Proceeding to the Medical Attendant in Cases of Acute Myocardial Infarction

\begin{tabular}{|c|c|c|}
\hline & Men & Women \\
\hline $\begin{array}{l}\text { Patient walked or went part of way on foot, } \\
\text { part by bus or tram } \\
\begin{array}{l}\text { Patient went by car, driving himself } \\
\text { was taken by car or taxi }\end{array} \\
\text { ". } \\
\text { Physician was" called to patient }\end{array}$ & $\begin{array}{r}48 \\
2 \\
20 \\
5 \\
27\end{array}$ & $\begin{array}{r}\frac{2}{7} \\
5 \\
17\end{array}$ \\
\hline Total No. of cases & 102 & 31 \\
\hline
\end{tabular}

TABLB III.-Time From the Onset of Acute Myocardial Infarction to Medical Attention

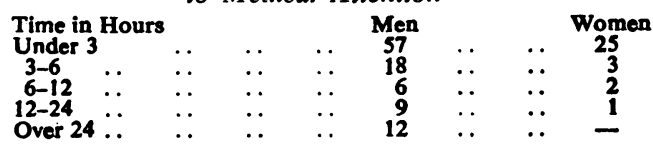

\section{Discussion}

The results of this investigation show that men did not, as a rule, take a rest immediately after the onset of acute myocardial infarction-as they should have done -but in spite of intense pain in the chest as many as $72 \%$ kept moving, and some of them walked long distances. Only 29 out of 102 ceased all activity at the onset of the attack: in 14 this cessation was due to shock and collapse-three of these patients fainted, and in one case the fall caused fracture of the skull. Thus in fact only 15 out of the 102 men deliberately took the right measures under the compulsion of the chest pain which accompanied the myocardial infarct. As the results show (Table 1 ), there was no great difference between men over 60 and those under 60 years of age. 
But the older men seemed to defy pain perhaps even more than the young. The women, on the other hand, differed radically from men in their response to the pain, for most of them ( 24 out of 31 ) stopped physical activity immediately the attack began.

The group of men contained numerous cases in which the total disregard of the condition, even when the patient was aware of the danger to life, appears incomprehensible. Mustering all his will-power, the patient continued to be physically active in spite of the relentlessly crushing pain in the chest and a sustained fight against loss of consciousness. Such an attitude is illustrated by the following two typical case histories.

Case 1.-A foreman aged 52 was cycling to his work. On the way he had a race with a youth, and by accident rode into the back wheel of his rival, so that he fell and the bicycle was damaged. As he was pushing his damaged bicycle he had a sudden attack of intense pain in the chest. Though he was hardly able to stand on his feet, he refused the help offered by passers-by, and instead of leaving his bicycle he struggled along, pushing it all the way to his workplace, a distance of about $1 \mathrm{~km}$. In the courtyard his vision became blurred and he sank down to a sitting position. Other workmen saw this and helped him in, but he lost consciousness in the lift. He was taken to hospital by car. Examination revealed a myocardial infarct in the posterior wall. His recovery was uneventful. He admitted afterwards that he had never before experienced such severe pain as he had during the attack.

Case 2.-A blacksmith aged 72, who had been treated for myocardial infarction about a year before, had a severe attack of pain in the chest while at work at the forge. The pain was so intense that it brought him down to his knees. The foreman hurried to help him and proposed to take him to hospital by car. This offer, as he admitted later, annoyed him a great deal, especially as he did not particularly like his superior. He struggled to his feet saying that he could get to the hospital on his own feet and was in no need of the "carriages of grand folks." He left the forge on foot, but did not go to the hospital ; instead, he walked home, a distance of about $1 \mathrm{~km}$. On several occasions he was forced to sit down on a step or lean against a wall when the pain. in the chest drained all strength from his legs and blurred his vision. At home the pain remained intense. At the insistence of his wife he went to the doctor in the afternoon. Even then he went on foot (about $300 \mathrm{~m}$.). The physician sent him at once to the hospital by taxi. The electrocardiogram showed changes typical of posterior-wall infarction (S.G.O.T. was 335 units on admission). He died in hospital three weeks later.

A suiprising point in Case 2 is that, though the patient had had a serious myocardial infarct a year before, he appeared to be none the wiser. A similar observation was made in other cases. In all, 29 men had had a previous myocardial infarct, and coronary insufficiency had been diagnosed in 19 others. Only 13 out of these 48 men who should have been aware of the serious implications of the pain in the chest took appropriate measures at the onset of the attack. Of the rest, eight walked 20-50 m., five walked 50-100 m., 14 walked 100-500 m., four walked 0.5-1 km., and another four walked over $1 \mathrm{~km}$. This might lead to the conclusion that little can be gained by instructing patients, but some of them said later that they had not known how dangerous all effort was in that condition.

Among the men who were at work at the time of the attack there were 12 in whom damage to the coronary artery had been previously diagnosed or who had had a previous myocardial infarct. But only six of these stopped work at the onset of the attack, whereas the other six tenaciously kept on for at least an hour.
Among the men who went on with their work in spite of the attack, five were later forced to stop on account of shock, which was so severe that they could not remain standing, however hard they tried. The following is an example of such extraordinary endurance.

Case 3.-An electrician aged 47 had a severe attack of pain while at work. Bathed in cold sweat, he sank to the floor, but a short rest revived him. He then resumed work and kept on till the end of the workday (for about four hours) as he considered that the factory could not manage without him. From time to time he had to sit down because of faintness. After work he walked home. In the afternoon -it was a Saturday-the pain subsided. He spent the Sunday in bed, and as a dull ache persisted he decided to go to hospital next day. But he considered it his duty to go first to the factory to arrange a substitute for himself, thinking that the running of the factory might otherwise be endangered. He stayed at work for four hours on Monday morning, with the pain increasing again. After handing over to his substitute, he made his way to the hospital, partly by tram, partly on foot. Electrocardiography showed extensive changes characteristic of myocardial infarct. The state of shock in which he was admitted could not be totally rectified. He died about 40 hours later. Necropsy confirmed the diagnosis of extensive posterior-wall infarct.

The response of the women to the pain was entirely different from that of the men. All the women who were at work stopped working at once after the onset of myocardial infarction.

The mode by which they proceeded to the doctor or the hospital also reflects the men's defiance of pain. Here again the women took a much more realistic view. It seems almost incredible that, regardless of the intense pain caused by the myocardial infarct, nearly half of the men (48 out of 102) walked all the way to the medical attendant or went partly on foot and partly by bus or tram. In most cases this was obviously not due to lack of money, for on inquiry most of these men explained that as they usually moved about town on foot they saw no reason for departing from their habit.

McLeod (1949) found that many of the 28 American patients with acute myocardial infarction walked a shorter or a longer distance after the onset of the attack. In his series the duration of the activity was as follows: 11 patients kept moving for 5 to 15 minutes, five for 15 minutes to one hour, four for one to two hours, and seven for 2 to 15 hours. In comparison with his results, the duration of the activity in the Finnish series (Table III) was somewhat longer. McLeod is of the opinion that this walking after the onset of acute myocardial infarct is due to the fact that the patient's "instinctive response to the pain is effort (manifested as walking) lasting from five minutes to several hours." But at least in those cases in which the physical effort was prolonged I should be inclined to think that the activity was not merely a manifestation of restlessness, but that the patient had forced himself to physical exertion regardless of the pain.

The results of the present investigation raise the question whether the unwise response to the symptoms of acute myocardial infarction-especially obvious in the men-might be a contributory factor in the mortality from this disease. It seems evident that if physical effort is obstinately prolonged in spite of the pain due to the attack the outcome may well be fatal. The following case illustrates this point.

Case 4.-In 1947 I treated a policeman aged 51 for coronary insufficiency. The man was fully aware of his condition. One day $I$ had a telephone call to his home 
and was told that he had suddenly died, a course of events common enough in this disease. However, in the dead man's home I met a friend and colleague of his, whose story of the patient's last moments was as follows. Both policemen were out on duty when my patient had a sudden attack of severe pain in the chest. He was on the point of collapsing, but, supported by his friend, he just managed to remain standing, pale and bathed in sweat. Nitroglycerin did not alleviate the pain. When his friend proposed taking a taxi to the hospital, he refused, saying: "Since we have started on foot, we shall go on foot. There is no pain in the world strong enough to make me stop." He managed to walk the distance of about $400 \mathrm{~m}$. to his home and even to mount four flights of stairs to his flat on the second floor, the lift being out of order. Then, having opened the front door, he fell down dead.

It is a well-known fact that mortality from acute myocardial infarction is much higher among men than among women. In Finland the average life-span of men is, according to Kannisto (1951), 6.5 years shorter than that of women. Kannisto came to the conclusion that this difference between men and women, which is apparently greater in Finland than anywhere else, is largely due to the high mortality of middle-aged and old Finnish males from cardiac trouble. Among the causes of death acute myocardial infarction is of especial significance. The present investigation shows that there is a remarkable difference in the response of men and women to the symptoms of an attack, and to the pain of angina pectoris, and it may well be that this difference in part accounts for the high mortality from acute myocardial infarction among men in Finland.

\section{Summary}

A report is presented on the physical exertions of 102 men and 31 women immediately after the onset of acute myocardial infarction.

Only $28 \%$ of the men stopped all physical activity at once or soon after the onset of the attack. The majority (72\%) continued to be active in spite of intense pain, even walking considerable distances, remaining at work, and so on. It was obvious that in many cases they had been able to keep up their efforts only by straining their will-power to the utmost. But even the severest pain did not seem to be a strong enough check to prevent. them from moving.

The majority of the women (about 77\%) went to rest immediately at the onset of the attack under the compulsion of the symptoms.

The response of the men was as unwise among those under 60 as among those over 60 years of age. The men who had had a previous myocardial infarction or previously diagnosed coronary insufficiency were only slightly more prudent. However, the view was taken that something might be gained by instructing patients more carefully.

It is suggested that the physical activity continued by men in spite of the symptoms of the attack may be a contributory factor in the mortality from acute myocardial infarction.

REFERENCES

Blumgart, H. L. (1955). In R. L. Cecil and R. F. Loeb's Textbook of Medicine, 9th ed., p. 1328. Saunders, Philadelphia and London

Friedberg, C. K. (1949). Diseases of the Heart. Saunders, Philadelphia and London

Kannisto, V. (1951) Duodecim, 67, 1108.

Levine, S. A. (1958). Clinical Heart Disease, 5th ed. Saunders, Philadelphia and London.

McLeod. S. W. (1949). Ann. intern. Med., 30, 757.

Miller, H. R. (1942). Angina Pectoris, 2nd ed. Heinemann, London.
Scherf, D., and Boyd, L. J. (1947). Cardiovascular Diseases. Lippincott, Philadelphia, London, and Montreal.

Warburg, E. (1943). In K. Faber's Nordisk Laerebog $i$ Intern Medicin, Sth ed. Nordisk Förlag, Kobenhavn. White, P. D. (1944). Heart Disease, 3rd ed. Macmillan, New
York.

\section{METASTATIC ARGENTAFFINOMA} SECRETING 5-HYDROXYTRYPTAMINE IN A PATIENT WITH A PATENT FORAMEN OVALE

\author{
BY
}

H. R. I. WOLFE, M.S., F.R.C.S. ALAN DAVIES,* M.S., F.R.C.S.

A. P. MATHIAS, Ph.D.

AND

M. SCHACHTER, M.D., C.M., M.Sc.

From University College Hospital and Depariments of Biochemistry and Physiology, University Cullege, Lundon

Evidence has recently accumulated that 5-hydroxytryptamine (5-H.T.) is a specific product of the enterochromaffin cell (Barter and Pearse, 1953; Erspamer, 1954), and many of the signs and symptoms associated with carcinoid tumours seem to be directly attributable to the release of large amounts of this substance into the circulation (Page, 1958). There are, however, some facts which are not readily explicable in terms of 5-H.T. mediation. For example, the valvular and endocardial changes which are almost always associated with carcinoid with flushing attacks cannot with certainty be accounted for by 5-H.T. Some carcinoid patients exhibit a histamine-like flush which is greatly reduced by antihistamine drugs. They may also have histaminuria (Waldenström et al., 1956). In others, diarrhoea, which is usually a severe symptom, is absent. It has been reported that some carcinoids contain little or no 5-H.T., and the suggestion has been made that these may constitute a group secreting 5-hydroxytryptophan (5-H.T.P.) rather than 5-H.T. (Sandler and Snow, 1958). Lastly, Lembeck (1954) has presented evidence of the presence of large amounts of a pharmacologically active substance in a carcinoid tumour in addition to 5-H.T. The studies on the present case are presented with these points in mind.

\section{Case Report}

An able seaman, aged 26, while serving in the Roval Navy in Malaya in 1951 became aware of recurrent attacks of flushing which mainly involved his face. Artacks of diarrhoea, associated with colicky pain in the right iliac fossa, began the following year and eventually became so severe that he was invalided home. Because these attacks persisted and became increisingly severe he was admitted to hospital in 1954, as a possible case of amoehic dysentery, but evidence of this infection was never found. At this time the heart was norrnal, and an $x$-ray examination of the chest showed no evidence of either pulmonary or cardiac disease. Because of further attacks of pain he was admitted to a hospital in Epsom in 1955, as a possible case of chronic appendicitis. Laparotomy showed that the mesentery was cicatrized, contracted, and filled with discrete softish glands, but some were hard and matted. A number of small discrete white nodules were also noted in the liver. The

*At present Senior Surgical Registrar, Hammersmith Hospital and Postgraduate Medical School, London. 